\title{
Cold Application and Breathing Exercises to Reduce Pain and Anxiety During Chest Tube Removal
}

\author{
Naglaa Mohamed EL Mokadem, Shimaa EL-Sayed Ibraheem \\ Medical-Surgical Nursing Department, Faculty of Nursing, Menoufia University, Shebin AL Khom, Egypt
}

Email address:

naglaae@yahoo.com (N. M. EL Mokadem), Shimaa553@yahoo.com (S. EL-Sayed I.)

To cite this article:

Naglaa Mohamed EL Mokadem, Shimaa EL-Sayed Ibraheem. Cold Application and Breathing Exercises to Reduce Pain and Anxiety During Chest Tube Removal. American Journal of Nursing Science. Vol. 6, No. 4, 2017, pp. 285-292. doi: 10.11648/j.ajns.20170604.12

Received: May 4, 2017; Accepted: May 18, 2017; Published: July 4, 2017

\begin{abstract}
Chest tube insertion following chest trauma or Coronary Artery Bypass Grafting (CABG) surgery is a frequent practice. Patients who undergo chest tube removal experience moderate to severe pain. Patients always described chest tube removal as a painful and frightening experience. Cold application and deep breathing exercise are effective nonpharmacological techniques to reduce pain and anxiety during chest tube removal. The aim of the study was to examine the effect of cold application and breathing exercises technique on pain and anxiety level during chest tube removal. A convenient sample of 120 patients. A quasi experimental design was used (study/control). Surgical intensive care unites at Menoufia University Hospital, Shebin EL-Kome. Visual Analog Scale for Pain (VAS) used to measure pain intensity during chest tube removal. Hamilton Anxiety Scale used to measure the anxiety level during chest tube removal. There was a statistically significant difference between study and control group regarding pain intensity post intervention. There was a statistically significant difference between study and control group regarding anxiety level post intervention. Using cold application and breathing exercise during chest tube removal is an effective practice to reduce pain intensity and anxiety level during chest tube removal. Encourage critical care nurses to develop practice guidelines for pain management during chest tube removal including application of cold and deep breathing exercise as a non pharmacological measure during chest tube removal.
\end{abstract}

Keywords: Chest Tube Removal, Pain, Anxiety, Breathing Exercises, Cold Application

\section{Introduction}

Insertion of chest tube following chest trauma or Coronary Artery Bypass Grafting surgery is a frequent practice [1]. Chest tube facilitates drainage of air and blood from the pleural, pericardial or mediastinal cavity. [2]. Patients who undergo chest tube removal experience moderate to severe pain. This pain results from the chest endothelial tissue which is adhered to the tube tip and at the time of tube removal the pulling force will shear this adhesion causing severe pain [3]. Patients always describe chest tube removal as a painful and frightening experience [4].

Anxiety and discomfort are unpleasant feeling that can be resulted from pain associated with chest tube removal. Anxiety is an emotion characterized by activation of the sympathetic nervous system which increases heart rate, blood pressure, respiration, and muscle tone [5]. The critical care nurse plays an important role for pain management during chest tube removal using non-pharmacological pain-relieving methods such as cold application and breathing exercise instead of administration of analgesic or pain-relieving drugs such as opioids and Non Steroidal Anti Inflammatory Drugs (NSAID) which is the most common intervention used for pain management during chest tube removal. Administration of pain killer medications is associated with side effects such as respiratory distress, nausea, itching and gastrointestinal bleeding [4].

Cold applications are commonly used as a nonpharmacological method for pain relief through slowing down tissue metabolism and nerve conduction velocity locally and also has vasoconstrictive, anti-inflammatory, antispasmodic and analgesic effects [6]. Deep breathing exercise is another non-pharmacological technique in pain management [4]. Deep breathing is defined as the absence of physical, mental, emotional tension, and can assist in the management of pain both physiologically and psychologically. Physiologically, relaxation leads to a reduction in or reversal of the sympathetic response to pain 
leading to a decrease in oxygen consumption, blood pressure, heart rate, and respiration. Psychologically, distraction is a built-in component of relaxation and impacts pain management by decreasing the cognitive awareness of pain [6].

There is evidence that application of cold and deep breathing exercise can control pain, decrease anxiety and increase the threshold of pain [7]. Also several clinical trials suggested that the use of cold application and deep breathing exercise can be a potential solution for the pain management during chest tube removal as it has been proved that the application of cold is effective for pain relieving during chest tube removal than other sedative medications $[2,3,6]$.

Definition of Variables

Pain: is theoretically defined as "an unpleasant sensory or emotional experience associated with actual or potential tissue damage" [8]. In the present study, pain was operationally defined as the obtained individual score on Visual Analog Scale (VAS) [3]

Anxiety: is theoretically defined as "an emotion characterized by feelings of tension, worried thoughts and physical changes like increased blood pressure" [9]. In the present study, anxiety was operationally defined as the obtained individual score on Hamilton Anxiety Scale [10].

Aim of the study

The aim of the current study was to examine the effect of cold application and deep breathing exercises on pain intensity and level of anxiety during chest tube removal.

Hypotheses

(1) Patients who will receive cold application and deep breathing exercises intervention are more likely to experience less pain during chest tube removal than patients who will receive routine hospital care.

(2) Patients who will receive cold application and deep breathing exercises intervention are more likely to experience less anxiety level than patients who will receive routine hospital care.

\section{Methods}

\subsection{Research Design}

A quasi experimental design (study - control) was used to test the study hypotheses.

\subsection{Setting}

The current study was conducted at surgical intensive care unite at Menoufia University Hospital, Shebin EL-Kome, Menoufia Governrat, Egypt.

\subsection{Sample}

A convenient sample of 120 critically ill adult patients recruited from the surgical ICUs at Menoufia University Hospital, Shebin EL-Kome. The sample size was determined based on power analysis. A significance level of 0.05 , a statistical power of 0.80 and a small effect size as calculated from previous study [19]. Patients were approached to participate in the study if they met the study inclusion criteria which include: a) adult patient age from 19 to 65years old; b) able to use the visual analog scale (VAS); c) Hemodynamically stable without any cardiac medication; d) and patient who have one or two mediastinal or pleural chest tubes. Patients were excluded from the study if they have a) mechanical ventilation support; b) and unconscious or cognitively impaired because patients with these conditions cannot report pain and anxiety during chest tube removal. Patients who met the study inclusion criteria were divided alternatively and randomly into four equal groups, 30 patients each. The study group (I) received cold application only with cooling gel pack; the study group (II) received deep breathing exercises only; the study group (III) received combined cold application with cooling gel pack and deep breathing exercise; and the control group (IV) received a routine hospital car.

\subsection{Tools of Data Collection}

a) Interviewing Questionnaire to collect sociodemographic data such as age, sex, educational level and clinical data which include type of chest tube and the number of days of chest tube was inserted.

b) Visual Analog Scale for Pain (VAS): The VAS is a onedimensional measure of pain intensity [3]. The VAS is a self completed by the respondent. The respondents were asked to place a line perpendicular to the VAS line at the point that represents their pain intensity. The score is determined by measuring the distance on the $10-\mathrm{cm}$ line between the zero "no pain" anchor and the patient's mark, providing a range of scores, Score of 10, a higher score, indicates greater pain intensity.

Test-retest reliability has been shown to be good, but higher among educated $(\mathrm{r}=0.94, \mathrm{P}=0.001)$ than illiterate patients $(\mathrm{r}=0.71, \mathrm{P}=0.001)$ before and after attending a cardaic or rheumatology outpatient clinic [11]. The construct validity was tested in patients with a variety of cardaic diseases, the pain VAS has been shown to be highly correlated with a 5-point verbal descriptive scale and a numeric rating scale with correlations ranging from $0.71-$ 0.78 and $0.62-0.91$, respectively). The correlation between vertical and horizontal orientations of the VAS is 0.99[12].

c) Hamilton Anxiety Scale: Used to measure the severity of anxiety level [10]. The scale consists of 14 items, each item was scored on a scale of 0 (not present) to 4 (severe), with a total score range from $0-56$, where $<17$ indicates mild severity, 18-24 mild to moderate severity and 25-30 moderate to severe severity. The internal consistency of the scale was tested in a study of two hundred fifty seven adult. The Cronbach's alpha was 0.95 for the total scale [9]. In the current study, the test-retest reliability of the total Scale score was 0.90 at nine patients with a period of two weeks interval.

\subsection{Data Collection Procedure}

The permission for conducting the study was obtained from the Faculty of Nursing and an official letter was issued 
to Menoufia University Hospital for seeking permission to carry out the study after explaining the purpose of the study.

\subsection{Ethical Consideration}

Patients who met the study inclusion criteria consented to participate in the study. During the intial interview, each participant was given a verbal explanation about the purpose, procedure, benefits of participating in the study and what was expected from him / her. The researcher explained that participation in the study is voluntary and the patient can withdraw from the study at any time without penalty and can refuse to participate in the study. Patients were assured that the information would be confidential to assure the confedentiality and anonymity of the participates information. It was explained that there is no cost to participate in the study.

\subsection{Pilot Study}

Was conducted on $10 \%$ of the study sample (Twelve patients) to test the practicality and applicability of the questionnaire and detect the problems that may be encountered during the data collection. It also helpe to estimate the time needed to fill in the questionnaire. Patient who participated in the pilot study were excluded from the final analysis of the sample.

Procedure (Intervention): Patients who met the study inclusion criteria was interviewed individually by the researcher in the intensive care units before starting the session of therapy.

All groups were matched against the study inclusion criteria as much as possible in relation to age and sex. A total sample of 120 adult patients with one or two chest tube were randomly assigned into four equal groups, 30 patients each. Assigning the participants to the three studied groups and one control group was done by writing the participants names on slips of paper and place it in a container and mixe well, and then drawn out one at a time until assigning the required sample size. The study group (I) received cold application only with cooling gel pack (cold group, $\mathrm{n}=30$ ); the study group (II) received deep breathing exercises only (breathing exercises group, $\mathrm{n}=30$ ); the study group (III) received combined cold application with cooling gel pack and deep breathing exercise (cold application with breathing exercise group, $\mathrm{n}=30$ ); and the control group (IV) received routine hospital car (control group, $\mathrm{n}=30$ ).

The First Interview: The first time the researcher met the participants considered the baseline measure. Data collection were obtained from participants in the surgical intensive care unite at Menoufia University Hospital at Shebin EL-Kome which includes 1) socio demographic questionnaire and 2) clinical data. During the first interview, the researcher explained to the participants how to use Visual Analog Scale to assess pain intensity during chest tube removal and how to use Hamilton Anxiety Scale to measure anxiety level. Also, the researcher explained to the participants that the pain intensity and anxiety level will be measured at four time points at 10 minutes before chest tube removal, immediately, 15 and 30 minutes after chest tube removal.

The Study Group: After physician decision to remove the chest tubes. Patients who assigned to the study group (I) received cold application with cooling gel pack. Cold gel packs were kept in the freezer for at least 2 hours and then were wrapped with gauze and were applied to the area surrounding the chest tube for 15 minutes. The researcher asked the patients to rate the pain intensity, and anxiety level they were felt with the chest tube in place. Pain intensity and anxiety level were measured for 10 minutes before, immediately, 15 and 30 minutes after chest tube removal.

Cold Application Technique: cold gel packs were used to reduce the body temperature around the chest tube during undressing. A single layer of sterile gauze pad was placed around the skin area of pericardial tube insertion (according to the cardiac surgery ICU regulations, pericardial tube is the first tube to be removed) and cooling packs $(14 \times 18)$ was twisted in gauze and was placed on top of it. Cold application was placed over chest tube removal area for 15 minutes. (Duration of cold application was determined to achieve the therapeutic effect of cold therapy, which requires cooling down tissues for at least 12 minutes [2]. Complete aseptic technique was followed during the procedure. After removal of the cooling packs, the physician removed the pericardial tube within 1-2 minutes. The intensity of pain and the anxiety level were measured 10 minutes before, immediately, 15and 30 minutes after chest tube removal.

Deep Breathing Exercise Technique: In the breathing exercises group, Participants were instructed to inhale calmly and deeply through their nose and exhale slowly through semi-closed lips, all with closed eyes for 5 minutes. The last 5 minutes of cold application, the researcher asked the participants to do breathing exercise and then the chest tube was removed.

The Control Group: All participants in the three studied groups and the control group were asked to loosen any tight clothes and they positioned in semi-fowler position and a pillow was set below their heads and knees in order to ensure their comfort. At the day of chest tube removal, all participants were prepared by administering $1 \mathrm{~g}$ Acetaminophen intravenously 60 minutes before the chest tube removal time. Pain intensity and anxiety level were measured 10 minutes before, immediately, 15 and 30 minutes after chest tube removal.

\subsection{Data Analysis}

Results were statistically analyzed using SPSS version 20 (SPSS Inc., Chicago, IL, USA). $X$ Square was used for Quantitative data. One way ANOVA (F test), repeated measures ANOVA test and Pearson's correlation were used for parametric data. Kruskal -Wallis test, Friedman test, Wilcoxon signed rank test and Spearman correlation were used for non-parametric data. $\mathrm{P}$ value $\leq 0.05$ is set to be significant. 


\section{Results}

Characteristics of the Sample: One hundred and twenty adult patients who attended the surgical intensive care unite at Menoufia University Hospital at Shebin EL-Kome were approached over a four months period from the beginning of September 2016 to the end of December 2016.

The mean age of the participants in the control group was $41.25 \pm 10.70$ and the mean age of the participants in the studied groups I, II and III were $40.25 \pm 10.98,37.55 \pm 14.12$ and $39.15 \pm 10.99$ respectively. The majority of participants
(80\%) in the control group and $(70 \%, 60 \%$, and $66.67 \%)$ in the studied group I, II, III were highly educated. The mean duration of chest tube insertion of the participants in the control group was $5.30 \pm 1.80$ days and the mean duration of chest tube insertion of the participants in the studied groups I, II, III were $5.85 \pm 1.98,5.65 \pm 1.49, \quad 5.05 \pm 1.39$ days respectively. Regarding the type of chest tube, $60 \%$ of participants in the control group and $(73.33 \%, 70.0 \%$, and $76.67 \%$ ) in the studied groups I, II, III had Pleural chest tube. See table (1)

Table 1. Socio- Demographic Characteristics of the Studied Groups.

\begin{tabular}{|c|c|c|c|c|c|c|c|c|}
\hline $\begin{array}{l}\text { Socio-demographic } \\
\text { characteristics } \\
\text { Age }\end{array}$ & \multicolumn{2}{|c|}{$\begin{array}{l}\text { Control Group } \\
(\mathrm{n}=\mathbf{3 0})\end{array}$} & \multicolumn{2}{|c|}{$\begin{array}{l}\text { Study Group I (Cold } \\
\text { application only) }(n=30)\end{array}$} & \multicolumn{2}{|c|}{$\begin{array}{l}\text { Study Group II (Breathing } \\
\text { exercises only) }(n=30)\end{array}$} & \multicolumn{2}{|c|}{$\begin{array}{l}\text { Study Group III (Cold application+ } \\
\text { Breathing exercises) }(n=30)\end{array}$} \\
\hline Mean \pm SD & \multicolumn{2}{|c|}{$41.25 \pm 10.70$} & \multicolumn{2}{|c|}{$40.25 \pm 10.98$} & \multicolumn{2}{|c|}{$37.55 \pm 14.12$} & \multicolumn{2}{|c|}{$39.15 \pm 10.99$} \\
\hline Sex & No & $\%$ & No & $\%$ & No & $\%$ & No & $\%$ \\
\hline Male & 18 & 60.0 & 21 & 70.0 & 19 & 63.33 & 22 & 73.33 \\
\hline Female & 12 & 40.0 & 9 & 30.0 & 11 & 36.67 & 8 & 26.67 \\
\hline \multicolumn{9}{|l|}{ Education Level } \\
\hline Illiterate & 2 & 6.67 & 3 & 10.0 & 4 & 13.33 & 3 & 10.0 \\
\hline Secondary & 4 & 13.33 & 6 & 20.0 & 8 & 26.67 & 7 & 23.33 \\
\hline High & 24 & 80.0 & 21 & 70.0 & 18 & 60.0 & 20 & 66.67 \\
\hline \multicolumn{9}{|l|}{ Type of Chest Tubes } \\
\hline Pleural & 18 & 60.0 & 22 & 73.33 & 21 & 70.0 & 23 & 76.67 \\
\hline Retrosternal & 5 & 16.67 & 2 & 6.67 & 4 & 13.33 & 3 & 10.0 \\
\hline $\begin{array}{l}\text { Retrocardial } \\
\text { Duration of Insertion }\end{array}$ & 7 & 23.33 & 6 & 20.0 & 5 & 16.67 & 4 & 13.33 \\
\hline Mean \pm SD & \multicolumn{4}{|c|}{$5.30 \pm 1.80$} & \multicolumn{2}{|c|}{$5.65 \pm 1.49$} & 5.05 & \\
\hline
\end{tabular}

Table 1 showed that there were no statistically significant differences between all studied groups I, II, III and control group related to all socio- demographic characteristics.

Table 2. illustrated that the mean pain scores at the four time points (before, immediately, 15 and 30 minutes) after chest tube removal. There was no statistically significant difference in the baseline pain intensity among the all study groups and control group $(P>0.05)$. Posthoc multiple comparisons revealed that there was statistically significant reduction in pain intensity in all studied groups compared with the control group immediately, 15 and 30 minutes after chest tube removal $(P<0.001)$.

Table 2. Effect of Cold Application and Breathing Exercises on Pain Intensity Post Intervention.

\begin{tabular}{|c|c|c|c|c|c|c|c|c|}
\hline \multirow[t]{2}{*}{ Pain Intensity } & \multirow{2}{*}{$\begin{array}{l}\text { Control } \\
\text { Group } \\
(n=30) \\
\text { Mean } \pm \text { SD }\end{array}$} & \multicolumn{2}{|c|}{$\begin{array}{l}\text { Study Group I (Cold } \\
\text { application only) }(n=30)\end{array}$} & \multicolumn{2}{|c|}{$\begin{array}{l}\text { Study Group II (Breathing } \\
\text { exercises only) }(n=30)\end{array}$} & \multicolumn{2}{|c|}{$\begin{array}{l}\text { Study Group III (Cold } \\
\text { application+ Breathing } \\
\text { exercises })(n=30)\end{array}$} & \multirow[t]{2}{*}{ Test of sig } \\
\hline & & Mean \pm SD & Post hoc test & Mean \pm SD & Post hoc test & Mean \pm SD & Post hoc test & \\
\hline Pre intervention & $4.40 \pm 1.09$ & $4.35 \pm 1.98$ & $=0.900$ & $4.40 \pm 1.09$ & $=0.682$ & $4.25 \pm 0.91$ & $\mathrm{P}=1.0$ & $\begin{array}{l}\text { Kruskal-Wallis } \\
0.23 \\
(\mathrm{P}=0.972)\end{array}$ \\
\hline $\begin{array}{l}\text { Immediately after } \\
\text { chest tube } \\
\text { removal }\end{array}$ & $4.0 \pm 0.85$ & $2.0 \pm 0.72$ & $<0.001 * *$ & $2.15 \pm 0.72$ & $<0.001 * *$ & $1.60 \pm 0.50$ & $<0.001 * *$ & $\begin{array}{l}\text { Kruskal-Wallis } \\
46.93 \\
\left(\mathrm{P}<0.001^{* *}\right)\end{array}$ \\
\hline $\begin{array}{l}15 \text { min after chest } \\
\text { tube removal }\end{array}$ & $4.30 \pm 1.03$ & $2.65 \pm 0.67$ & $<0.001 * *$ & $2.95 \pm 0.82$ & $<0.001 * *$ & $2.40 \pm 0.68$ & $<0.001 * *$ & $\begin{array}{l}\mathrm{F} \\
21.59 \\
(\mathrm{P}<0.001 * *)\end{array}$ \\
\hline $\begin{array}{l}30 \text { min after chest } \\
\text { tube removal }\end{array}$ & $4.35 \pm 0.98$ & $2.75 \pm 0.71$ & $<0.001 * *$ & $3.10 \pm 0.78$ & $<0.001 * *$ & $2.50 \pm 0.68$ & $<0.001 * *$ & $\begin{array}{l}\mathrm{F} \\
20.87 \\
\left(\mathrm{P}<0.001^{* *}\right)\end{array}$ \\
\hline $\mathrm{P}$ value & $>0.05$ & $<0.001 * *$ & & $<0.001 * *$ & & $<0.001 * *$ & & \\
\hline
\end{tabular}

* Significant **highly significant \# Friedman test

Figure 1 showed that there was a high statistically significant difference in pain intensity immediately, 15 and 30 minutes after chest tube removal between studied and control groups post intervention. 


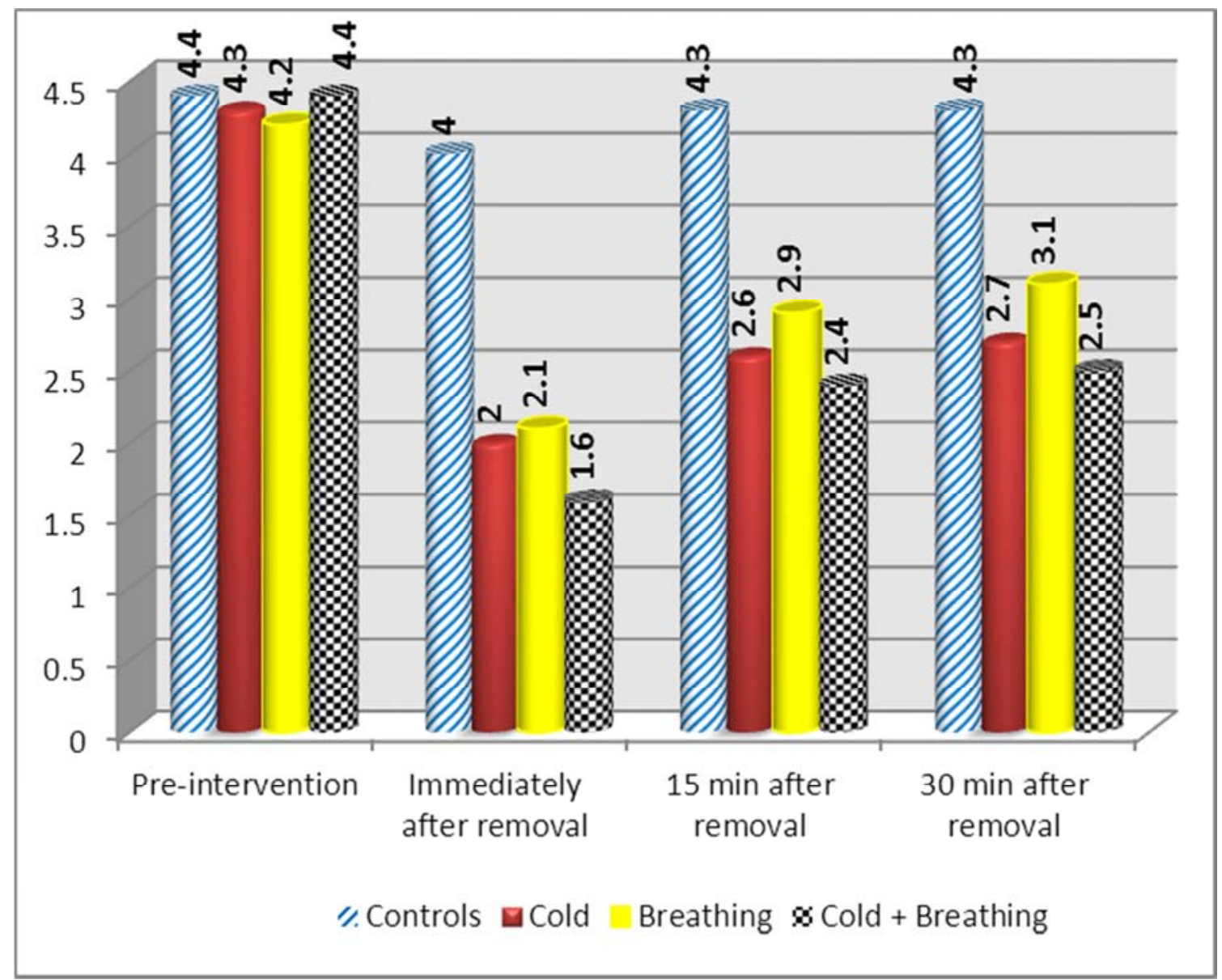

Figure 1. Effect of Cold Application and Breathing Exercises on Pain Intensity Post intervention.

Table 3 revealed that there was no statistically significant difference in the mean anxiety scores among all study groups and control group $(P>0.05)$. Posthoc multiple comparisons revealed that there was a statistically significant difference in the mean anxiety scores at immediately, 15 and 30 minutes after chest tube removal between control and all studied groups I, II, III post intervention $(P>0.001)$.

Table 3. Effect of Cold Application and Deep Breathing Exercises on Anxiety level Post Intervention.

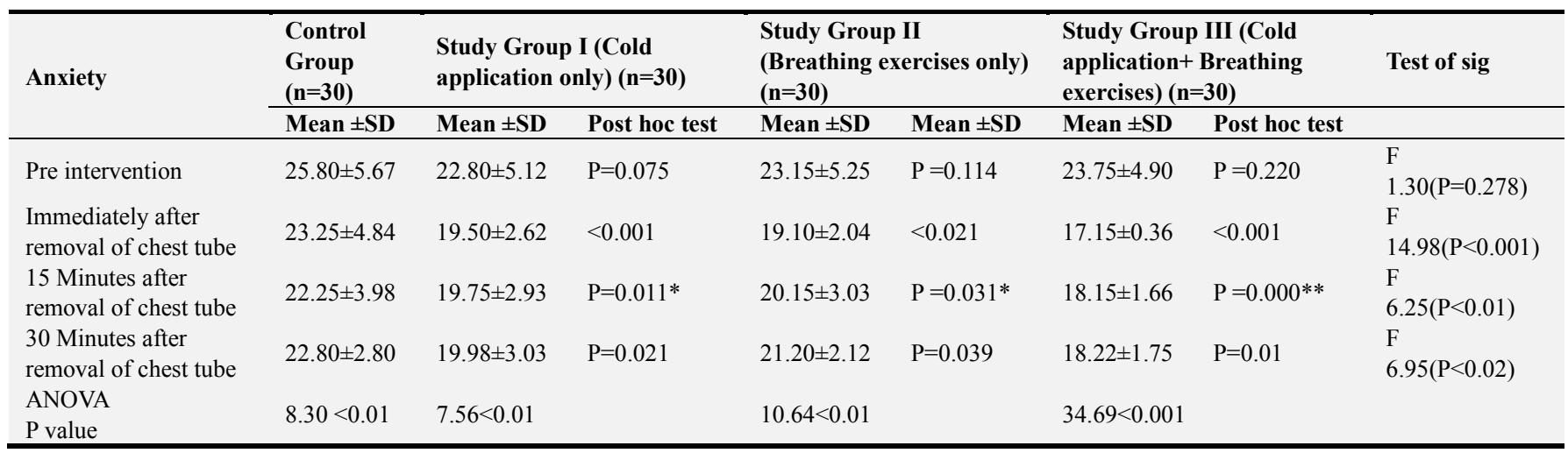

$<0.05$ is significant

Figure 2 revealed that there was a statistically significant reduction in the mean anxiety scores immediately, 15 and 30 minutes after chest tube removal in all studied groups compared with the control group. 


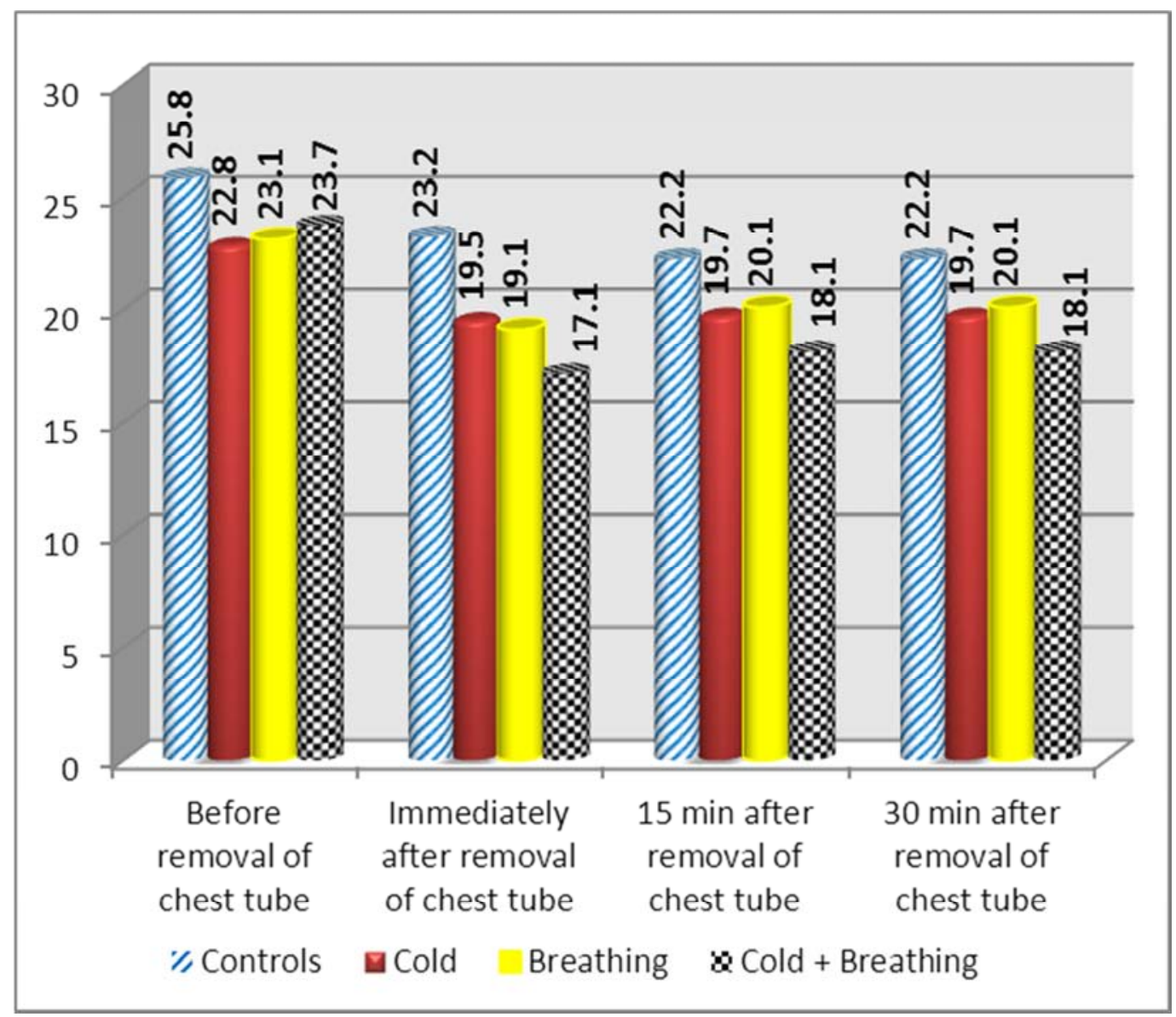

Figure 2. Effect of Cold Application and Breathing Exercises on Anxiety level Post Intervention.

\section{Discussion}

The current study hypothesized that the patients who received cold application and deep breathing exercises are more likely to experience less pain during chest tube removal than patients who received a routine hospital care. The findings of the present study revealed that there is a statistically significant reduction in pain intensity at the three measurement points (immediately, 15 and 30 minutes) after chest tube removal in the studied groups (cold application group, breathing exercise group and cold application and breathing exercise combined group) compared to the control group. The findings of the current study are similar to what was reported by $[15,4,14,2,13,6]$ whom examined the effect of cold application combined with a breathing exercises technique on pain intensity during chest tube removal and found that using cold application combined with breathing exercises technique was effective in reducing pain intensity. National Institutes of Heart Lung \& Blood [16] supported the hypothesis that pain can be reduced or decreased by using ice therapy in adult immediately after chest tube removal and found that the frequency of pain intensity was reduced by more than $60 \%$.

The findings of the current study are similar to what was reported by Ertug and Ulker [17] who assessed the effect of combined cold application and breathing exercise on pain during chest tube removal in a controlled clinical trial included140 patient. Cold application combined with breathing exercise was applied to the experimental group and the pain intensity was measured at 4 time points; prior to the cold application and breathing exercise, before removing chest tube, immediately after the removal of the chest tube, 15 minutes and 30 minutes after the removal of the chest tube. The findings of the study revealed that there was a significant reduction in pain intensity with cold application combined with breathing exercise group compared to the control group.

Also, the current findings are similar to what was reported by Casey et al., [18] whom evaluated multiple methods, including cold therapy versus breathing exercise versus combined cold compresses with breathing exercise on the incidence of pain during chest tube removal. The result showed that the incidence of mild pain was $74 \%$ lower in people who used combined ice application with breathing exercise; lower by $66 \%$ in patient who received cold application only and $46 \%$ lower in individuals who used breathing exercise only.

However, the study findings are different from what was reported by Sauls [19] who found that cold therapy was not very efficient in reducing pain. The participants in the cold application group reported that pain intensity at 15 and 30 minutes after chest tube removal was similar to the control group. A possible explanation of Sauls' findings could be the short duration of cold application therapy (10 minutes only). 
While the evidence suggests that the physiological effects of cold therapy appear when it continues for 20 minutes.

In addition, The study findings are different from what was reported by Rafii, et al. [20] who studied the breathing technique to reduce pain at the time of chest tube removal and found that the breathing or relaxation method was not an effective way to reduce chest tube removal -related pain and there was no significant statistical differences in pain intensity between the study group and the control group. A possible explanation of the findings may be due to that the intervention focused on breathing exercise alone.

The current study hypothesized that patients who received cold application and deep breathing exercises combined are more likely to have less anxiety level than patients who received routine hospital care. The findings of the present study revealed that a statistically significant decrease in anxiety level immediately, 15 and 30 minutes after chest tube removal in the studied groups compared to the control group. The finding of the present study is similar to what was reported by $[15,22,21,13,9,5]$ whom studied the effectiveness of using cold back and breathing exercise on anxiety level during chest tube removal and found that there was a statistically significant decrease in anxiety level in the study group compared to the control group.

Similar findings have been reported by [23] who studied middle-aged subjects with one or two chest tube where they randomized to receive routine care (control group) or receive ice therapy for 20 minutes combined with breathing exercise before chest tube removal (study group). The study findings suggested that using ice application and breathing exercise can decrease total mean score of anxiety level immediately, 15 and 30 minutes after chest tube removal in the study group post intervention compared to the control group.

However, the study findings are different from what was reported by [19] who examined the effect of using ice on anxiety among critically ill patients who had chest tube and found that there was no significant difference of the anxiety level between the study group and the control group. A possible explanation of the study findings may be due to that the majority of sample in this study was hemodynamiclly instable, have chronic diseases, and have long stay in the hospital, all of which increases anxiety level. Also, the study findings are different from what was reported by [20] who studied using the cold bag and breathing technique to reduce anxiety level at 30 minutes after chest tube removal and found that there was no significant statistical difference of the anxiety level between the study and the control group 30 minute post chest tube removal. A possible explanation of the study findings may be due to the short duration of performing the breathing exercise.

\section{Conclusions}

Cold application combined with breathing exercise is an effective technique to reduce the intensity of pain and anxiety level during chest tube removal. Cold application and breathing exercise technique is a safe, inexpensive, and a non- pharmacologic nursing intervention that can be recommended as a pain relief technique during chest tube removal.

Nurses make important decisions regarding application of non-pharmacologic therapeutic interventions for pain management.

\section{Recommendations}

Increase the critical care nurses awareness about the effectiveness of using cold application in conjunction with breathing exercise as a non-pharmacologic therapeutic interventions for reducing pain and anxiety level during chest tube removal.

Further assessment of this technique can help critical care nurses to develop practice guidelines for pain management during chest tube removal and advance the current practices, thus improving patient care and ultimately improving patients' outcomes.

Explore the influence of other confounding variables, such as age, gender, educational level and prior pain experience to evaluate the effectiveness of cold application and breathing exercise as a pain management intervention.

Replication of this study is recommended with several design changes such as, using large sample size; using a randomized selection to achieve appropriate representation of the studied population; and conducting the study in a larger scale to include multicenter.

\section{References}

[1] American Heart and Lung Association. Nursing management of chest drains. Nursing Standard. (2013); 17, 45-54. Available at: http://www.healthline.com/health/chest-tubeinsertion\#afterward6

[2] Demir Y, Khorshid L. The effect of cold application in combination with standard analgesic administration on pain and anxiety during chest tube removal: A single- blinded, randomized, double-controlled study. Pain Manag Nurs. (2010); 11: 186-96.

[3] Cline ME, Herman J, Shaw ER \& Morton RD. Standardization of the visual analogue scale. Nursing Research. (1992); 41(6): 378-380.

[4] Al-Otaibi, RA., Mokabel, F M. and AL-Ghuneimy Y. The Effect of Cold Application on Pain and Anxiety during chest tube removal. J Am Sci (2013); 9(7): 13-23.

[5] Seers, K. and Dawn C. Relaxation techniques for acute pain management: A systematic review. Journal of Advanced Nursing (1998); March. 27 (3): 466 -475.

[6] Friesner SA, Curry DM, Moddeman GR. Comparison of two pain management strategies during chest tube removal: relaxation exercise with opioids and opioids alone. Heart Lung (2006); 35 (4): 269-76.

[7] Etoch SL, Ulcer S, Codkun O, man L E, K Anatli Y. Cold therapy in migraine patients: Open labels, Non controlled, pilot study. Evidence based Complement Alternat Med. Dec J. (2006); 3(4): 489-93. 
[8] Broscious SK. Music: an intervention for pain during chest tube removal after open heart surgery. American Journal of Critical Care (1999); 8, 410-415.

[9] Houston S, Jesurum J. The quick relaxation technique: Effect on pain associated with chest tube removal. Appl Nurs Res. (1999); 12: 196-205.

[10] Hamilton M. (1988). The assessment of anxiety states by rating. Br J Med Psychol. 32: 50-55.

[11] Carson MM, Barton DM, Morrison CC \& Tribble CG. Managing pain during mediastinal chest tube removal. Heart Lung (1994); 23, 500-505.

[12] Scott J, Huskisson E. Vertical or horizontal visual analogue scales. Ann Rheum Dis (2001); 38: 560.

[13] Biteman, K., and Dalton, T. Management of procedural pain: Empowering nurses to care for patients through clinical nurse specialist consultation and intervention. Clinical Nurse Specialist (2009); 23 (3): 131-137.

[14] Mazloum SR, Abbasi Tehnizi M, Kiannejad A, Gandomkar F. Effect of applying ice bag on pain intensity associated with chest tube removal after cardiac surgery. Horizon Med Sci. (2012); 18: 109-14.

[15] Gorgi HM, Nesami BM, Ayyasi M, Ghafari R, Yazdani J. Comparison of ice packs application and relaxation therapy in pain reduction during chest tube removal following cardiac surgery. North Am J Med Sci. (2014); 6: 19-24.

[16] National Institutes of Heart Lung \& Blood. Reduction of pain intensity after chest tube removal. (2009) Available at http://www.nhlbi.nih.gov/index.htm.
[17] Ertug V. Ulker S. The effect of cold application on pain due to chest tube removal. Journal of Clinical Nursing (2012); 21: 784-90.

[18] Casey E, Bostanci K, Kuriakose D, McGeary S, Hayes N, Phelan D, Buggy D. The Effect of Cold Application in Combination with Standard Analgesic Administration on Pain and Anxiety during Chest Tube Removal: A Single-Blinded, Randomized, Double- Controlled Study. Pain Management Nursing (2008). 11(3), September: 186-196.

[19] Sauls J. The use of ice for pain associated with chest tube removal. Pain Manag Nurs. (2002); 3: 44-52.

[20] Rafii F, Mohammadi Fakhar F, Jamshidi Orak R, Inanloo M. Effect of Jaw relaxation on pain intensity of burn dressing. Iran J Critical Care Nurs. (2010); 3: 51-6.

[21] Gift, A., Bolgiano, C. and Cunningham J. Effect of Ice back application on pain and anxiety during chest tube removal. Heart Lung (2010). 20 (2): 131-7.

[22] Deneuville M, L aureano Filho JR, de Oliveira e Silva ED, Batista CI, Gouveia FM. The influence of cryotherapy on reduction of swelling, pain and trismus after third- molar extraction: a preliminary study. Journal of American Dental Association. (2012) Jun; 1 36(6): 774-8.

[23] Hariedy N, Mohammed M, Abd El-Alaziz M and Mohammed L. The Impact of Implementing of Standardized Nursing Care toward Patient with a Chest Tube to Reduce Pulmonary Complications after Thoracotomy. Journal of American Science (2011). 7 (12). 